\title{
Two Heads May Not Be Better than One in Writing to Learn Spanish as a Second Language
}

\author{
Ya-Chin Tsai, Ph.D. \\ Department of Foreign Languages, National Chiayi University \\ 85 Wunlong Village, Minsyong Township \\ Chiayi County 621, Taiwan \\ Tel: 886-5-2263411 E-mail: tsai@mail.ncyu.edu.tw
}

Received: 02-09- 2012

doi:10.7575/ijalel.v.2n.1p.180
Accepted: 18-10- 2012

Published: 01-01- 2013

\begin{abstract}
This study investigated two approaches to writing to learn Spanish as a second language. Eight undergraduate students were exposed to task-based language learning and a traditional approach in a counter-balanced manner to learn Spanish verbs from writing stories. While the participants made significant improvements in morphosyntactic accuracy over time, their performance with regard to syntactic complexity was deteriorated. When the two approaches were compared, no significant differences were found in accurate use of Spanish reflexive verbs or complexity of the stories. Although the number of language-related episodes and accurate use of reflexive verbs were positively related, the correlation did not reach a significant level. Due to the nature of this small-scale study, generalizability of these results is limited.
\end{abstract}

Keywords: task, interaction, output, accuracy, complexity, language-related episode, second language acquisition, reflexive verb

\section{Introduction}

\subsection{Task in SLA}

There is an ongoing interest in the application of task-based language learning (TBLL) to enhance second language acquisition (SLA) (Bygate, Skehan, \& Swain, 2001; Ellis, 2003). In recent decades, TBLL has become widely adopted in syllabus designs (Johnson, 2003). Ellis (2003, pp. 9-10) elaborates the concept of a task, as follows: (a) it is a work plan, (b) it involves linguistic activity, (c) it requires primary attention to be on meaning, (d) it allows learners to select the linguistic resources they will use, (e) it requires learners to function primarily as language users rather than learners, and (f) it has a clearly defined non-linguistic outcome.

Unlike the traditional approaches, TBLL is characterized by the high levels of interaction that occur among learners (Larsen-Freeman, 2000). However, it remains a matter of concern to what extent such peer interaction actually fosters SLA. Specifically, it remains unclear whether TBLL is more efficient in stretching learners' second-language development beyond a level that is possible to attain with a traditional approach (Storch, 1999).

The use of TBLL is premised on the principle that two heads are better than one (Lantolf \& Poehner, 2008), and thus, during their interactions, learners' attention is drawn more closely to the form/linguistic problems they encounter (Doughty \& Williams, 1998). However, little research has been conducted to find out whether TBLL is more effective than traditional approaches in raising learners' attention to Spanish morphosyntactic elements.

\subsection{Purpose of the Study}

The purpose of this study is three-fold: (1) to compare the actual performance yielded from TBLL with that of a traditional approach, (2) to evaluate the learning outcomes from using both approaches together, and (3) to examine language acquisition in relation to learners' attention to linguistic problems. The following three research questions are investigated in this study:

1. What impact did the two approaches together have on learners?

2. Was TBLL better than the traditional approach with regard to accuracy and complexity of the students' written output?

3. Did the students' attention to linguistic problems affect the accurate use of Spanish verbs?

\subsection{Role of Output in SLA}

Swain (1995) stated that input alone is not enough to develop higher grammatical competence, and thus proposed the Output Hypothesis. She argued that it is necessary to produce output to compensate for the insufficiency of relying on input alone to achieve learning goals. Giving learners more chances to produce output can encourage them to process 
language in more depth. Because their attention will be drawn to form (Swain, 1995), producing output facilitates the development of grammatical competence. However, the Output Hypothesis was not intended as a replacement for the Input Hypothesis. Instead, the former was proposed as an addition to the latter (Ellis, 2003).

Output has at least three key functions with regard to SLA (Swain, 1995). First, learners' attention is channeled to form/linguistic problems in their interlanguage system. When producing output, they have the opportunity to notice any gaps between what they intend to express and what they already have acquired in their interlanguage system (Swain \& Lapkin, 1995). The second function is related to learners' hypotheses testing. Producing output provides learners with opportunities to test their hypotheses with regard to linguistic well-formedness or comprehensibility. When a learner's interlanguage system is pushed to generate output, it is more likely that language acquisition will take place (Taron \& Liu, 1995). The third function is concerned with metalinguistics. Reflection on language use motivates learners to contemplate the linguistic resources they have at hand. Simply stated, when producing output learners have a chance to evaluate their interlanguage system in the form of metatalk. All three functions have been considered important in triggering language acquisition.

\subsection{Peer Interaction in SLA}

Social activities have been reported to maximize the zone of proximal development (Lantolf \& Poehner, 2008). Goss, Zhang and Lantolf (1994) investigated the effects of peer interaction on a grammaticality judgment. In their study, some participants carried out the judgments independently, while the others worked in pairs or triads. The results showed only a slight variation between individual performance and pair/triad performance, though pair/triad performance achieved a higher rate of accuracy with regard to grammatical features. However, their study suffers from a few flaws. The major flaw, for instance, lies in the use of a grammaticality judgment as an assessment, as there is some controversy over the reliability and validity of this type of instrument (Leow, 1996).

Although sociocultural theory emphasizes the pedagogical value of TBLL, traditional approaches are not without value (Storch, 2002). For example, Storch (1999) contended that traditional approaches result in more complex and lengthier output than TBLL, albeit with less accuracy.

\subsection{Importance of attention in SLA}

Attention - identified by the occurrence of language-related episodes (LREs) during peer interaction (Swain \& Lapkin, 1995; Swain, 1998) - is one of the necessary conditions for SLA to occur. An LRE refers to "any part of a dialogue in which students talk about the language they are producing, question their language use, or other- or self-correct" (Swain, 1998, p. 70). LREs can be lexis-based or form-based (Swain \& Lapkin, 1998). Lexis-based LREs refer to comments on vocabulary items, while form-based LREs represent students' attention to the spelling of morphemes or specific syntactic structures.

The occurrence of LREs seems to serve as an index of language acquisition. Swain and Lapkin (1998) analyzed the LREs produced by students working together during a jigsaw activity, in which the students created a story based on pictures. Although the metatalk among the students was considered vital to improve accuracy, this conclusion was drawn from analysis on partial data. It is uncommon that the data were selectively analyzed to support the researchers' claims. Moreover, the researchers conceded that the number of LREs produced during peer interaction varied significantly across groups. Because the amount of time that the students spent on the activity also varied, the time factor might have affected the results.

\section{Method}

\subsection{Participants}

The participants were eight undergraduates who spoke English as their first language. Their previous learning experiences with Spanish were limited ( 0 to 1 year) and they had stayed in Spanish-speaking countries for only between 0 - 3 months.

\subsection{Materials \& Instruments}

Four similar sets of pictures were used for data collection (See the Appendix for an example). The pictures illustrated "Manuel's Daily Routine" (Knorre, Dorwick, Pérez-Gironés, Glass \& Villarreal, 1997, p. 133). Every picture depicted a routine activity, such as taking a bath, brushing teeth, or getting up in the morning. Similarities among the sets of pictures allowed linguistic comparisons.

\subsection{Target Items}

Spanish reflexive verbs in the present tense were selected as the target items to be assessed. Spanish is a pro-drop language, and conjugation is necessary to convey information regarding subject and tense. There are three necessary conditions to use reflexive verbs properly: (1) to conjugate a verb, (2) to supply a reflexive pronoun, and (3) to place a reflexive pronoun immediately before a conjugated verb. In declarative sentences, the reflexive pronoun, which is in agreement with the agent of the sentence, must be explicitly spelled out and placed before a conjugated verb. For irregular verbs, the vowel of the stem is conjugated for the subject.

The target items to be studied were acostarse (to go to bed), afeotarse (to shave), bañarse (to take a bath), ducharse (to take a shower), ponerse (to put on clothes), despertarse (to wake up), sentarse (to sit down), divertirse (to have a good time), dormirse (to fall asleep), peinarse (to comb), cepillarse (to brush), and vestirse (to get dressed). 


\subsection{Procedure}

The data collection period consisted of four sessions (pretest, traditional, TBLL, and posttest). After the pretest, four of the participants independently wrote a story for a set of pictures while an audio-recorder was used to capture their thinking aloud. The others constructed a story in pairs for the same pictures and their discussions were also recorded. Then, using a different set of pictures with the same theme, the two approaches were administered to the same participants in a counter-balanced fashion. Finally, all the participants took a posttest. Each participant created stories independently for the pre- and posttests, which were based on the content of the pictures they had seen in both approaches.

\subsection{Data Analysis}

\subsubsection{Accuracy}

The written stories produced by the participants were analyzed in terms of accurate use of morphosyntactic elementsi.e., the conjugations of the verbs, use of the reflexive pronouns, and word order. The accuracy of using a reflexive verb was scored by the following criteria:

$\circ$ use of a correct verb (occurrence: 1 ; absence: 0 )

○ conjugation (correct: 1 ; incorrect: 0 )

$\circ$ occurrence of a reflexive pronoun (occurrence: 1 ; absence: 0 )

○ form of the pronoun (correct: 1 ; incorrect: 0 )

- word-order of the verb and the reflexive pronoun (correct: 1 ; incorrect: 0 ).

For the accurate use of a verb, a total of five points stood for mastery, while zero points represented very poor performance.

\subsubsection{Complexity}

Complexity was measured in terms of number of sentences, the number of words, and the ratio of clauses to sentences. T-units, which have been used for English data, were not appropriate for data analysis in this study, because Spanish and English have different syntactic structures.

\subsection{Coding Procedure}

The recorded data was transcribed and analyzed for LREs (Swain, 1998), which were operationalized as follows, with examples taken from transcribed protocols:

1. Lexis-based LRE: talk related to participants seeking Spanish vocabulary or selecting among competing lexical items.

e.g., S1: OK, here we go putting on clothes, see? We always have these pictures, and I never know the words for them...

S2: Se desp, se des, -viste! Yeah, se viste.

S1: Isn't it viste like a look? Oh, that's vista.

S2: Vestir means to dress yourself-vestirse.

S1: Se viste? Ah, OK.

2. Form-based LRE: talk related to spelling or any aspect of Spanish morphemes or syntactic structure during story creation

e.g., S3: Uhhh, le gusta cantar en el baño. Asfiar? Asfiarse? Ah afeitarse afeitarse? Afeitarse?

\section{Results}

T-tests and correlation analyses were conducted. The stories written during the traditional approach were compared to those written during TBLL. The Pearson product-moment correlation coefficient $(r)$ was obtained to measure the relationship between LREs and accuracy. The participants' performance is displayed in Table 1.

Table 1. Pretest vs. posttest performance

\begin{tabular}{lcrrrr}
\hline & \multicolumn{2}{c}{ Pretest } & & \multicolumn{2}{c}{ Posttest } \\
& \multicolumn{2}{c}{$S D$} & & $M$ & \multicolumn{2}{c}{$S D$} \\
\hline Number of sentences & 11.50 & 4.07 & 6.12 & 2.41 \\
Number of words & 95.62 & 21.09 & 48.87 & 17.13 \\
Ratio & 1.45 & .20 & 1.58 & .33 \\
Accuracy & 13.25 & 5.06 & 18.12 & 7.43 \\
\hline
\end{tabular}

The stories were assessed in terms of complexity and accuracy. For Research Question One, three t-tests were performed for complexity. The t-test comparing the number of sentences in the pre- and posttest revealed a significant difference, $t(14)=-7.124, p<.01$. The t-test comparing the number of words produced in the pre- and posttests also 
revealed a significant difference, $t(14)=-6.53, p<.01$. However, the t-test comparing the ratios between the pretest and the posttest showed no significant difference, $t(14)=.99, p>.05$. One t-test was administered for accuracy. The pre- and posttest performances differed significantly in accuracy, $t(14)=2.39, p<.05$. In sum, the participants made progress in accuracy from the pretest to posttest, while the level of complexity decreased. The number of sentences and words significantly decreased, though the ratios of clauses to sentences did not differ significantly (Figure 1).

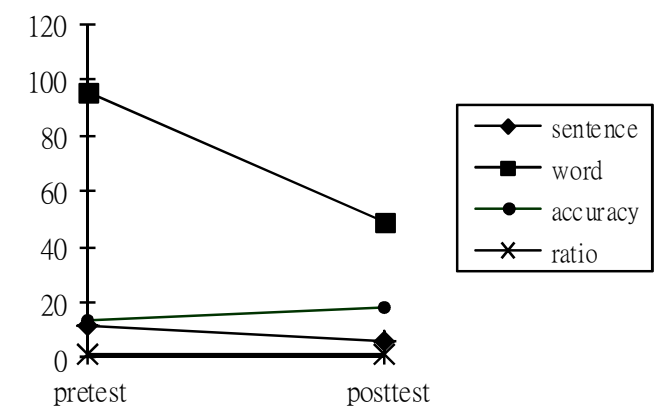

Figure 1. Pretest vs. posttest

For Research Question Two, t-tests were also conducted. The participants' performance is displayed in Table 2. The first t-test revealed no significant difference between the two approaches in the number of sentences, $t(10)=.11, p>.05$, while the second showed no significant difference in the number of words, $t(10)=.51, p>.05$. A third t-test comparing the ratios revealed no significant difference between the two approaches, $t(10)=.40, p>.05$, while the last t-test showed no significant difference in accuracy, $t(10)=1.9, p>.05$. In brief, the learning outcomes out of TBLL were not significantly different from those derived from the traditional approach with regard to accuracy and complexity.

Table 2. Traditional vs. Task-based

\begin{tabular}{lrrrr}
\hline & Traditional & \multicolumn{3}{c}{ Task-based } \\
\hline Number of sentences & \multicolumn{1}{c}{$S D$} & & $M$ & \multicolumn{2}{c}{$S D$} \\
Number of words & 8.12 & 1.45 & 8.25 & 2.21 \\
Ratio & 64.50 & 16.50 & 59.50 & 14.47 \\
Accuracy rate & 1.36 & .24 & 1.30 & .14 \\
& 14.00 & 8.83 & 23.75 & 6.94
\end{tabular}

For Research Question Three, a correlation analysis was conducted for LREs (ranging from 0 to 10) and the accurate use of reflective verbs. Although the LREs and accuracy rate were positively related, the correlation did not reach a significant level $(r=.5, p>.05)$. Moreover, due to the small sample size, this result has to be interpreted with caution.

\section{Discussion}

This study investigated two approaches to writing to learn Spanish morphosyntactic elements, and several findings were derived. First, accuracy seemed to be achieved at the cost of complexity. Second, TBLL did not outperform the traditional approach with regard to accuracy or complexity. Third, attention to linguistic problems, as revealed in the LREs, did not enhance complexity or accuracy to a significant degree.

The traditional approach used in conjunction with TBLL was found to enhance the accurate use of Spanish reflexive verbs. One possible explanation is that the two approaches together drive the participants to acquire the verbs by repeatedly producing output. That is, more time spent practicing output increases the accuracy rate. Because of the similarity among the sets of pictures, the participants' attention was constantly concentrated on how to conjugate the verbs accurately, which resulted in a higher accuracy rate. However, the accuracy rate seems to have been achieved at the cost of complexity. Due to limited attentional capacity in cognition, there appears to be a trade-off effect between accuracy and complexity (VanPatten, 1996).

Compared with the traditional approach, TBLL alone did not seem to optimize learning outcomes. Interestingly, this finding does not support Storch (1999), who argued that TBLL has a positive effect on accuracy and that the traditional approach leads to greater complexity. This study found that TBLL alone led to neither greater complexity nor accuracy, in comparison with the traditional approach. It is possible that the participants in this study had never engaged in TBLL previously in their Spanish learning. Owing to their unfamiliarity and lack of experience with TBLL, the participants were unable to benefit from it.

This study challenges the conventional view of the relationship between attention to linguistic problems and learning outcomes, as revealed in the correlation between LREs and accuracy. Indeed, one of the findings actually ran counter to those of prior research (Swain, 1998; Swain \& Lapkin, 1998), which highlighted the significant relationship between accuracy and attention to linguistic problems. It is suggested that LREs evolve naturally out of TBLL, whereas it might 
not hold true with regard to thinking aloud. It has been contended that thinking aloud protocols might not actually represent what was occurring in the learners' mind (Kuusela \& Pallab, 2002). It is undeniable that thinking aloud while writing is intrusive and may lead to cognitive overload. Therefore, we have good reason to believe that the thinkingaloud transcripts may have underrepresented the actual thinking that took place in the participants' minds. Furthermore, due to the small-scale nature of this study, the results should not be generalized. More work is needed to shed more light on the effects of TBLL and the traditional approach on SLA.

\section{Limitations}

This study has several limitations. First as a small-scaled study, the generalizability of the results is rather limited. In addition, since this study focused on the learning of Spanish reflexive verbs, the results should not be generalized to other grammatical structures.

\section{Recommendations}

Some recommendations are suggested here for future studies. First, more participants should be invited to verify the results, as well as increase external validity. Furthermore, TBLL should be implemented with different linguistic targets to examine its pedagogical effects. Finally, replication studies should be conducted to help us further clarify the issues raised in this work.

\section{Acknowledgement}

The author would like to thank the editor and anonymous reviewers for their valuable comments. Any errors that remain are my sole responsibility.

\section{References}

Bygate, M., Skehan, P., \& Swain, M. (Eds.) (2001). Researching pedagogic tasks: second language learning teaching and testing. Harlow, UK: Pearson.

Doughty, D. \& Williams, J. (Eds.) (1998). Focus on form in classroom second acquisition. Oxford: Oxford University Press.

Ellis, R. (2003). Task-based language learning and teaching. Cambridge: Cambridge University Press.

Goss, N., Zhang, Y., \& Lantolf, J.P. (1994). Two heads may be better than one: Mental activity in second-language grammaticality judgements. In Tarone, E. E., Gass, S. M., Cohen, A. D. (Eds.), Research methodology in secondlanguage acquisition (pp. 263-286). New Jersey: Lawrence Erlbaum.

Johnson, K. (2003). Designing language teaching tasks. Houndmills: Palgrave Macmillan.

Knorre, M., Dorwick, T., Pérez-Gironés, A. M., Glass, W.R., \& Villarreal, H. (1997). Puntos de partida: An invitation to Spanish. Boston, MA: McGaw-Hill company.

Kuusela, H., \& Pallab, P. (2002). A comparison of concurrent and retrospective verbal protocol analysis. American Journal of Psychology, 113, 387-404. http://dx.doi.org/10.2307/1423365

Lantolf, J. P. \& Poehner, M. E. (Eds.) (2008). Sociocultural theory and the teaching of second languages. London: Equinox.

Larsen-Freeman, D. (2000). Techniques and principles in language teaching (2 ${ }^{\text {nd }}$ ed.). New York: Oxford University Press.

Leow, R. P. (1996). Grammaticality judgment tasks and second language development. In. J. E. Alatis, C. A. Straehle, M. Ronkin \& B. Gallenberger (Eds.), Linguistics, language acquisition, and language variation: Current trends and future prospects (pp. 126-139). Washington, DC: Georgetown University.

Storch, N. (1999). Are two heads better than one? Pair work and grammatical accuracy. System, 27, $363-374$. http://dx.doi.org/10.1016/S0346-251X(99)00031-7

Storch, N. (2002). Patterns of interaction in ESL pair work. Language Learning, 52, 119-158. http://dx.doi.org/10.1111/1467-9922.00179

Swain, M. (1995). Three functions of output in second language learning. In G. Cook and B. Seidhofer (Eds.), For H. G. Widdowson: Principles and practice in the study of language (pp. 125-144). Oxford: Oxford University Press.

Swain, M. (1998). Focus on Form through Conscious Reflection. In C. Doughty \& J. Williams (Eds.), Focus on form in classroom second language acquisition (pp. 114-138). Cambridge: Cambridge University Press.

Swain, M., \& Lapkin, S. (1995). Problems in output and the cognitive processes they generate: A step towards second language learning. Applied Linguistics, 16, 3, 371-391. http://dx.doi.org/10.1093/applin/16.3.371

Swain, M., \& Lapkin, S. (1998). Interaction and second language learning: Two adolescent French immersion students working together. The Modern Language Journal, 82, 320-337. http://dx.doi.org/10.1111/j.1540-4781.1998.tb01209.x

Tarone, E., \& Liu, G. Q. (1995). Situational context, variation, and second language acquisition theory. In G. Cook \& B. Seidlhoffer (Eds.), Principle and practice in applied linguistics (pp. 107-124). Oxford: Oxford University.

VanPatten, B. (1996). Input processing and grammar instruction in second language acquisition. Norwood, NJ: Ablex. 


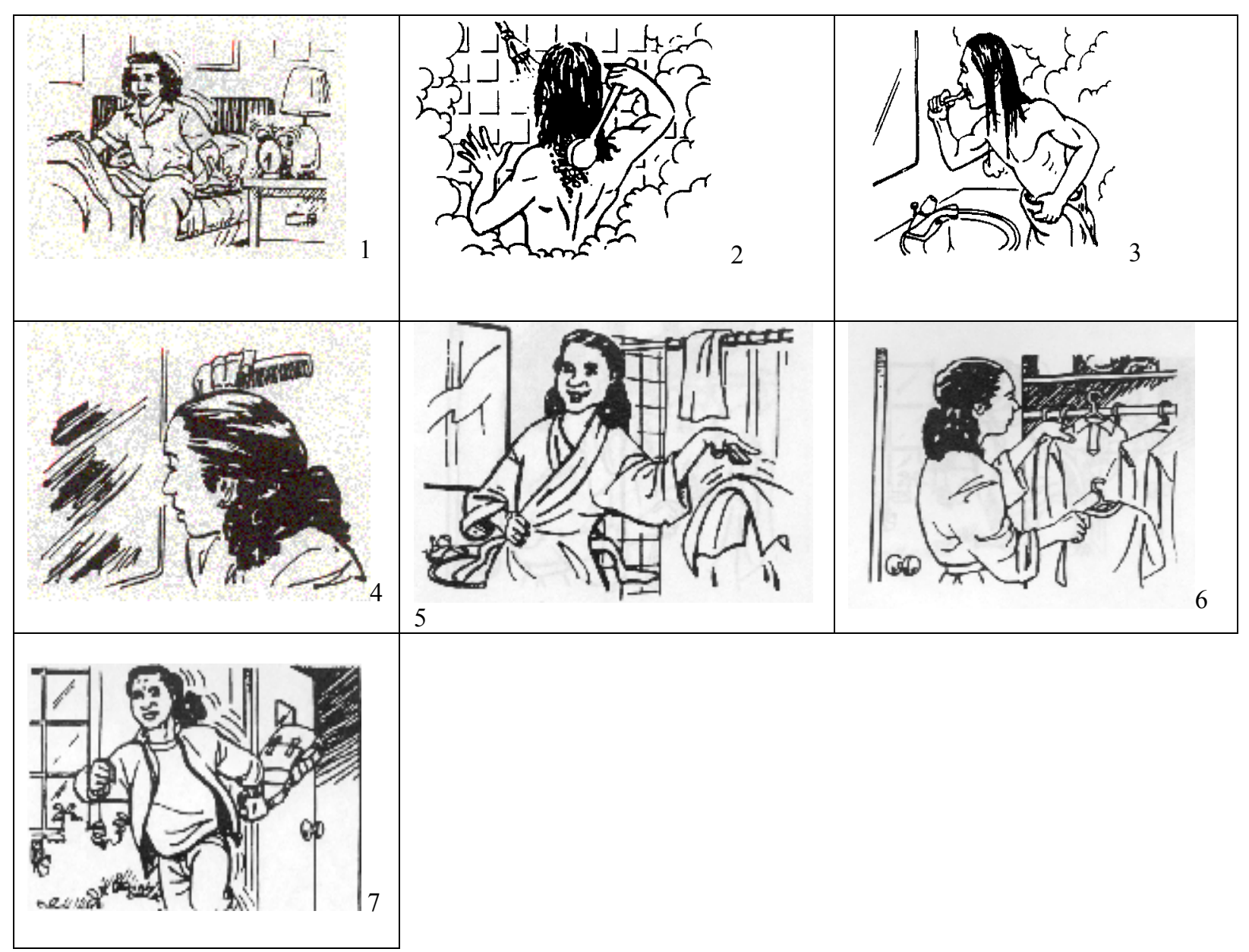

